(C) NIAB 2017. This is an Open Access article, distributed Plant Genetic Resources: Characterization and Utilization (2018) 16(3); 260-272 under the terms of the Creative Commons Attribution licence doi:10.1017/S1479262117000272 (http://creativecommons.org/licenses/by/4.0/), which permits unrestricted re-use,

distribution, and reproduction in any medium, provided the original work is properly cited.

ISSN 1479-2621

\title{
Characterization of West and Central African accessions from a pearl millet reference collection for agro- morphological traits and Striga resistance
}

\author{
F. T. Sattler ${ }^{1}$, M. D. Sanogo ${ }^{2}$, I. A. Kassari ${ }^{3}$, I. I. Angarawai ${ }^{4}$, K. W. Gwadi $^{5}$, H. Dodo ${ }^{6}$ and $^{2}$ \\ B. I. G. Haussmann ${ }^{1 *}$ \\ ${ }^{1}$ Institute of Plant Breeding, Seed Science and Population Genetics, University of Hohenheim, Stuttgart, \\ Germany, ${ }^{2}$ Institut d'Economie Rurale (IER), Cinzana, Mali, ${ }^{3}$ Institut National de la Recherche \\ Agronomique du Niger (INRAN), Maradi, Niger, ${ }^{4}$ International Crops Research Institute for the Semi-Arid \\ Tropics (ICRISAT), Kano, Nigeria, ${ }^{5}$ Lake Chad Research Institute (LCRI), Maiduguri, Nigeria and ${ }^{6}$ ICRISAT, \\ BP 12404, Niamey, Niger
}

Received 29 June 2017; Accepted 22 September 2017 - First published online 6 November 2017

\begin{abstract}
To promote the utilization of West and Central African (WCA) genetic resources of pearl millet [Pennisetum glaucum (L.) R. Br.], this study aimed at agro-morphological characterization of selected accessions from the pearl millet reference collection, established by the Generation Challenge Program and the International Crops Research Institute for the Semi-Arid Tropics (ICRISAT). A total of 81 accessions were included, comprising 78 landraces originating from 13, predominantly WCA countries and three improved cultivars. All 81 accessions were evaluated together with 18 checks for resistance to the parasitic weed Striga hermonthica (Del.) Benth. in an artificially infested field at one location in Niger. Determined by available seed quantity, 74 accessions were characterized together with seven checks in the rainy season 2009 in field trials under low-input and fertilized conditions in Nigeria, Niger and Mali, respectively. Wide ranges were observed for various traits. Several accessions were identified as sources for specific traits of interest, i.e. long panicles, high-grain density, earliness, Striga resistance and stable yielding across environments. The observed yield inferiority of all Genebank accessions compared with checks may indicate lost adaptation or inbreeding depression due to an insufficient effective population size during multiplication. A principal component analysis revealed an immense diversity but also strong admixture among the tested accessions, i.e. there were no clearly distinct groups. The seed of all genotypes is available from ICRISAT. The online availability of the characterization data is expected to facilitate efficient use of these pearl millet accessions by breeding programmes in WCA and worldwide.
\end{abstract}

Keywords: agronomic evaluation, genetic resources, low-input, pearl millet, Striga resistance

\section{Introduction}

Pearl millet [Pennisetum glaucum (L.) R. Br.] is a food security crop in the harsh drylands of Sahelian West and

*Corresponding author. E-mail: bettina.haussmann@uni-hohenheim.de
Central Africa (WCA) and in drylands of South Asia, especially India. Additionally, farmers use the stover as animal fodder and building material.

West Africa (WA) is a primary diversity centre of pearl millet (Brunken et al., 1977; Oumar et al., 2008; Tostain and Marchais, 1993). The International Crops Research Institute for the Semi-Arid Tropics (ICRISAT) is maintaining 
a collection of 22,888 accessions of the genus Pennisetum from 51 countries (Upadhyaya et al., 2007) with 13,185 accessions originating from Africa (Genesys, 2016). Characterization and agronomic evaluation of genetic resources is a prerequisite to identify trait-specific germplasm for crop improvement. Continuous, targeted diversification of breeding populations is important to assure long-term selection gains.

Pucher et al. (2015) studied 360 pearl millet accessions from 16 WCA countries at six locations in WA. Reported ranges for 13 agro-morphological traits reflected the tremendous pearl millet diversity in WCA. Bashir et al. (2013) found large variability for iron $(20-86 \mathrm{mg} / \mathrm{kg}$ ) and zinc (14-82 mg/kg) grain content among 225 pearl millets from Sudan, illustrating good scope for biofortification breeding. Significant genetic variation regarding phosphorus efficiency related traits was found among 46 landraces and 54 improved open pollinated varieties under phosphorus-fertilized and phosphorus deficiency conditions (Gemenet et al., 2015b). Large variability for numerous agro-morphological traits was also reported for pearl millet by Gemenet et al. (2014, 2015a), Haussmann et al . (2007), Pucher et al. (2014) and Upadhyaya et al. (2011).

All these studies facilitate the utilization of pearl millet genetic resources. However, no information is so far available about agro-morphological variation and adaptation to WCA of the pearl millet reference collection established by the Generation Challenge Program (GCP). Evaluation of GCP reference sets can serve to identify further traitspecific germplasm. Furthermore, development of genomic tools via association of trait variation with genetic differences could render breeding programmes more efficiently (Pattanashetti et al., 2016).

Pearl millet production constraints in WCA include low soil fertility, unpredictable drought, and high pressures of downy mildew (Sclerospora graminicola (Sacc.) J. Schroet.) and the parasitic weed Striga hermonthica (Del.) Benth. While some WCA farmers strive to intensify their production using fertilizer, many are unable to afford/access fertilizer, especially women. Therefore, identification of germplasm that can cope with low soil fertility and simultaneously produce stable yields is crucial. Kountche et al. (2013) reported the existence of genetic variation for Striga resistance in pearl millet and demonstrated a significant response to recurrent selection in a Striga-resistant genepool. Further screening of genetic resources for Striga resistance is required so that promising materials can be integrated into the genepool to assure longer-term selection gains or adaptation of the genepool to further environments.

The objectives of this study were therefore to:

(1) extend passport data of different WCA accessions within the GCP pearl millet reference collection;
(2) find sources of Striga resistance in pearl millet;

(3) determine relationship patterns of pearl millet accessions in WCA.

\section{Materials and methods}

\section{Selection of genetic material}

A total of 81 pearl millet accessions from the GCP pearl millet reference collection, maintained at ICRISAT-India were selected and successfully multiplied for this study (online Supplementary Table S1, Supplementary Fig. S1). The accessions were selected based on their WCA (including Sudan) origin due to a clear lack of adaptation and a very poor performance of non-WCA pearl millets in WCA environments (Padilla, 2007). To cover a potentially higher variability, three accessions were added from South Africa. The 81 accessions comprised 78 cultivated landraces and three improved cultivars. The 78 landraces originated from 13 countries (online Supplementary Fig. S1), namely Benin (1 accession), Burkina Faso (8), Cameroon (6), Central Africa (1), Ghana (4), Mali (9), Mauritania (1), Niger (15), Nigeria (14), Senegal (1), South Africa (3), Sudan (10) and Togo (5). The three improved cultivars originated from ICRISAT-Niger (2) and from a joint ICRISAT-Niger/ Institut d'Economie Rurale (IER, Mali) breeding programme (1). Wild accessions were discarded from the collection due to the risk of spreading as weed and contaminating valuable elite germplasm, and seed multiplications of the breeders.

\section{Seed multiplication}

Around $10 \mathrm{~g}$ of seed were obtained per accession from the collection holder. The multiplication of the 81 accessions was done at ICRISAT-Niger in the off-seasons 2008/2009 and February 2009 using manual 'sibbing' which simulates the natural out-crossing behaviour of the species. It consists of the following steps: (i) covering all emerging panicles with a parchment pollination bag; (ii) collecting pollen from several panicles of one accession; (iii) mixing the pollen collected from panicles of the same accession; (iv) distributing the pollen mixture onto other panicles of the same accession where only the female part flowers and no pollen is shed yet (protogyny); and (v) harvesting the (crossed) seed exclusively from the pollinated female panicles. This method largely corresponds to random mating and should reduce any possible inbreeding depression that may have occurred during previous regenerations - unless there were severe bottlenecks (i.e. very low number of plants effectively contributing to the next generation) in previous generations. Low effective population size $\left(N_{\mathrm{e}}<30\right.$ plants contributing to the next generation) for some accessions in the first off-season (due to germination problems and 
low seed quantities) was corrected with the second offseason multiplication effort for the majority of entries. It is therefore assumed that the majority of the genetically heterogeneous pearl millet accessions were properly sampled during the seed multiplication. However, it was not possible to produce enough seed per accession to test them in all environments. Considering thus only 74 accessions were used in all trials. The complete set was used at Sadoré in the Striga resistance trial.

\section{General trial conditions}

The field trials were conducted at three locations in WCA (online Supplementary Fig. S1) in 2009: Cinzana in Mali $\left(13^{\circ} 15^{\prime} 10^{\prime \prime} \mathrm{N}, 5^{\circ} 57^{\prime} 55^{\prime \prime} \mathrm{W}\right)$, Maiduguri in Nigeria $\left(11^{\circ} 50^{\prime} 0^{\prime \prime}\right.$ $\left.\mathrm{N}, 13^{\circ} 9^{\prime} 0^{\prime \prime} \mathrm{E}\right)$, and Sadoré in Niger $\left(13^{\circ} 14^{\prime} 0^{\prime \prime} \mathrm{N}, 2^{\circ} 17^{\prime} 0^{\prime \prime} \mathrm{E}\right)$. Planting dates differed considerably at the three sites, ranging from June 16 at Sadoré and July 9 in Cinzana to August 3 at Maiduguri (Table 1). The late planting at Maiduguri was due to religious clashes in July, followed by a drought spell. The trial sites differed in monthly rainfall and mean maximum and minimum temperatures (Table 1).

\section{Characterization trials under low-input and fertilized conditions in Niger, Nigeria and Mali}

For the agro-morphological characterization, the 74 accessions were randomized together with seven checks in a $9 x$ $9 \alpha$ lattice design with three replications. Plot size consisted of one row of $4.8 \mathrm{~m}$ length and $0.8 \mathrm{~m}$ between hills; rows were $0.75 \mathrm{~m}$ spaced $\left(4.2 \mathrm{~m}^{2} / \mathrm{plot}\right)$. Following locationspecific recommendations, seven hills were planted per plot in Maiduguri and Sadoré, while 10 hills were planted per plot in Cinzana. The seven checks included six improved varieties from WCA and one exclusive local variety at every location. Thinning was done to two plants per hill. The soil fertilization treatment levels were handled as separate environments. The trials were planted either side by side in the same field, or in different fields of the same station. Data collection was done in each plot for the following traits: number of hills after emergence (NHE) and number of hills at harvest $(\mathrm{NHH})$, seedling vigour (SVIG; $1-5,5$ being the best), number of hills infested by downy mildew (DM), days to $50 \%$ flowering (FLO; Julian days), panicle exertion $(\mathrm{cm})$, plant height (PHT; $\mathrm{cm}$ ), panicle length (PLE; $\mathrm{cm})$, panicle circumference (CIR; $\mathrm{cm})$, panicle compactness (CMP; $1-3,3$ being the best), number of productive panicles (NPH), panicle yield (PYD; $\mathrm{g} / \mathrm{m}^{2}$ ) and grain yield $\left(\mathrm{GYD} ; \mathrm{g} / \mathrm{m}^{2}\right)$. Stover yield (STYD; $\mathrm{g} / \mathrm{m}^{2}$ ) data were collected for Sadoré and Maiduguri, but not recorded in Cinzana at the low-input trial. Thousand grain weight (TGW) was recorded at Sadoré only. From these data, other traits were computed, such as the percentage of downy mildew infestation (DM \%), number of productive tillers/plant (TILL), the average panicle weight (APW; g) and the number of grains per panicle (NGP).

\section{The evaluation of Striga resistance in Niger}

The Striga resistance evaluation in an isolated field at Sadoré involved 81 accessions from the GCP reference collection plus 18 checks. The 99 entries were randomized in a fourfold replicated alpha design with 11 incomplete blocks per replication and nine plots per incomplete block. Each experimental unit consisted of one row of $3 \mathrm{~m}$ length. Spacing was $1.6 \mathrm{~m}$ between rows and $0.5 \mathrm{~m}$ between hills within rows ( 7 hills/plot; $5.6 \mathrm{~m}^{2} / \mathrm{plot}$ ). Thinning was done to two plants per hill. The field was artificially infested with Striga seeds collected near Sadoré on pearl millet in the previous year. Data collection in each plot comprised the

Table 1. Summary of weather data during characterization trials of West and Central African accessions of the GCP pearl millet reference collection

\begin{tabular}{|c|c|c|c|c|c|c|c|c|}
\hline \multirow{3}{*}{$\begin{array}{l}\text { Planting date } \\
\text { Month }\end{array}$} & \multicolumn{3}{|l|}{ Cinzana } & \multicolumn{2}{|l|}{ Maiduguri } & \multicolumn{3}{|l|}{ Sadoré } \\
\hline & \multicolumn{3}{|l|}{9 July 2009} & \multicolumn{2}{|c|}{3 August 2009} & \multicolumn{3}{|c|}{16 June 2009} \\
\hline & Rain (mm) & $\operatorname{TMAX}\left({ }^{\circ} \mathrm{C}\right)$ & $\mathrm{T} \mathrm{MIN}\left({ }^{\circ} \mathrm{C}\right)$ & Rain $(\mathrm{mm})$ & $\mathrm{T}\left({ }^{\circ} \mathrm{C}\right)$ & Rain $(\mathrm{mm})$ & $\operatorname{TMAX}\left({ }^{\circ} \mathrm{C}\right)$ & $\operatorname{T~MIN~}\left({ }^{\circ} \mathrm{C}\right)$ \\
\hline June & $(47)^{\mathrm{a}}$ & 44 & 21 & $(49)^{\mathrm{a}}$ & - & 60 & 37 & 26 \\
\hline July & 137 & 38 & 19 & $(92)^{\mathrm{a}}$ & - & 142 & 35 & 24 \\
\hline Aug & 141 & 36 & 21 & 266 & - & 202 & 32 & 24 \\
\hline Sept & 259 & 36 & 20 & 147 & - & 67 & 34 & 24 \\
\hline Oct & 25 & 39 & 18 & 71 & - & 22 & 37 & 25 \\
\hline Total rain/Average $\mathrm{T}$ & 561 & 38.6 & 19.8 & 484 & - & 494 & 35 & 24.5 \\
\hline
\end{tabular}

an brackets: rains that appeared before planting. 
following traits: NHE, NHH, SVIG, DM, FLO, PHT, PLE, CMP, NPH and PYD. In addition, the following Striga resistance related traits were assessed: Date of Striga emergence (DES; Julian days), number (NSx) and vigour (VIGx; 1-9, as defined by Haussmann et al. (2000), with nine being the best) of emerged Striga plants, with $x=$ at 66,86 and 105 days after planting. From these data, more comprehensive resistance measures were computed for each entry, such as Striga severity (SEVx; NSx * VIGx) at the different dates, area under Striga number progress curve (ASNPC) and area under Striga severity progress curve (ASVPC) as described by Haussmann et al. (2000).

\section{Statistical analysis}

First, the data were analyzed individually per environment (location $\times$ fertilization level) to estimate repeatabilities (single environment heritabilities) and to eliminate outliers for further comparisons, using the following model:

$$
Y_{i l m n}=\mu+G_{i}+R_{l}+B_{l m}+E_{l m n}
$$

where $Y_{\mathrm{ilmn}}$ is the observed phenotype; $\mu$ is the grand mean; $G_{i}$ is the effect of genotype $i ; R_{l}$ is the effect of replication $l ; B_{l m}$, is the effect of incomplete block $m$ nested in replication $l$; and $E_{l m n}$ the residual effect of the plot $n$ nested in block $m$ and replication $l$. The adjusted mean for each entry was calculated by regarding genotypic effects as fixed, while the other factors were treated as random. For estimating repeatabilities, the genotypic effects were regarded as random.

Finally, the data were analysed in a one-step approach. The following mixed model was designed under the assumption of heterogeneous error variance of environments:

$$
\begin{aligned}
Y_{i j k l m n} & =\mu+G_{i}+L_{j}+F_{k}+G L_{i j}+G F_{i k} \\
& +L F_{j k}+G L F_{i j k}+R_{j k l}+B_{j k l m}+E_{j k l m n},
\end{aligned}
$$

where $Y_{i j k l m n}$ is the observed phenotype; $\mu$ is the grand mean; $G_{i}$ is the effect of genotype $i ; L_{j}$, is the effect of location $j ; F_{k}$ is the effect of the fertilizer level $k ; G L_{i j}$ is the interaction effect of genotype $i$ and location $j ; R_{j k l}$ is the effect of replication $l$ in every location $\times$ fertilization combination; $B_{j k m}$, is the effect of incomplete block $m$ for every location $\times$ fertilization combination; and $E_{j k l m n}$, the residual effect of the plot $n$ nested in block $m$, replication $l$, and for every location $\times$ fertilization combination. Adjusted means were calculated by regarding genotypic and fertilization effects as fixed, while the other factors were treated as random. For estimating variance components, the genotypic effects were regarded as random.

Variance components significance was tested using the likelihood ratio test for model comparison (Stram and
Lee, 1994). Broad-sense heritability $\left(H^{2}\right)$ was calculated as:

$$
H^{2}=\sigma_{\mathrm{g}}^{2} \times\left(\sigma_{\mathrm{g}}^{2}+\frac{\sigma_{\mathrm{gl}}^{2}}{L}+\frac{\sigma_{\mathrm{gf}}^{2}}{F}+\frac{\sigma_{\mathrm{glf}}^{2}}{L F}+\frac{\sigma_{\mathrm{e}}^{2}}{L F R}\right)^{-1},
$$

where $\sigma_{\mathrm{g}}^{2}$ represents the genotypic variance, $\sigma_{\mathrm{gl}}^{2}$ the genotype by location interaction variance, $\sigma_{\mathrm{gf}}^{2}$ the genotype by fertilization interaction variance, $\sigma_{\mathrm{glf}}^{2}$ the genotype by location by fertilization interaction variance, and $\sigma_{e}^{2}$ the residual variance. $L, F$ and $R$ are the number of locations, fertilization levels and replications, respectively.

The Pearson coefficients of correlation were calculated to determine relationships among the observed traits, using adjusted means. The respective significance levels were Bonferroni-adjusted.

The Additive Main Effect and Multiplicative Interaction (AMMI) analysis was performed based on lattice-adjusted entry means per location for grain yield, in order to assess patterns of genotype by environment interaction. The principal component analysis (PCA) was based on centred adjusted means across environments of all above-mentioned traits having heritabilities higher than $70 \%$ to avoid strong environmental bias on the PCA.

All calculations were performed within the R-environment v. 2.14.2 and v. 3.2.3 (R Development Core Team, 2012). Mixed model analysis was conducted using the ASReml v. 3.0 package for the R-environment (Butler et al., 2009) and the AMMI was calculated using the agricolae package v. 1.2-8 (de Mendiburu, 2016).

\section{Results}

\section{Differentiation for agro-morphological traits under low-input and fertilized conditions}

Genotypic differences among the tested accessions were significant and repeatability estimates were reasonably high for most phenological, morphological and performance traits. Repeatabilities ranged from $16 \%$ for seedling vigour at the Cinzana low-input environment to $98 \%$ for flowering time at the Cinzana high-input environment (online Supplementary Table S2). When comparing repeatabilities in the low-input versus fertilized treatments across all traits, no clear tendencies could be observed, except for stover yield, where repeatability estimates tended to be higher under high-input conditions. In Cinzana, repeatabilities were lower for seedling vigour and higher for downy mildew susceptibility than in Maiduguri and Sadoré. The ranges of trait expression at each site were large and significant among the tested accessions (online Supplementary Table S2), indicating the existence of, e.g. extra-early or late flowering accessions, accessions with very long or short panicles, downy mildew resistant and high-yielding accessions. Correlation coefficients between 
the high- and low-input treatments for the single locations (Cinzana, Maiduguri and Sadoré) were all positive and significant $(\alpha=0.05)$, except for seedling vigour in Cinzana and downy mildew in Sadoré (online Supplementary Table S3).

The combined analysis across sites and soil fertilization treatments revealed highly significant genetic variance for all traits (Table 2). Broad-sense heritability estimates ranged from 0.39 for seedling vigour to 0.96 for panicle length. Separation of the genotype by environment $(G \times E)$ interaction revealed significant genotype by location $(G \times L)$ effects for all shown traits, except PLE. Genotype by soil fertilization $(G \times F)$ interaction was only significant for stover yield and panicle yield. The threefold interaction $(\mathrm{G} \times \mathrm{L} \times \mathrm{F})$ was significant for downy mildew susceptibility, plant height and panicle circumference.

Genetic variances explained the largest part of the total variance for all traits except seedling vigour and downy mildew susceptibility. The variance ratio of $G$ to $G \times L, G$ to $G \times F$ and $G$ to $G \times L \times F$ for seedling vigour was $1: 1.5$, 1:0 and 1:0 and for downy mildew susceptibility 1:2.3, 1:0 and 1:0.52. This led to relatively low broad-sense heritabilities for these traits $(0.39$ for seedling vigour and 0.46 for downy mildew susceptibility). However, the variance ratios were 1:0.33, 1:0 and 1:0.07 for plant height, 1:0.02, 1:0 and 1:0.02 for PLE and 1:0.35, 1:0.09 and 1:0 for grain yield leading to high broad-sense heritabilities of 0.87 , 0.96 and 0.74 , respectively.

The local checks (G81), which differed among locations, had the highest yield in the combined analysis. Five out of six improved checks (G75, G76, G77, G78 and G79) were performing well in the individual environments and were among the eleven best in terms of grain yield in the combined analysis (online Supplementary Table S4). Individual accession means are made available for each location-soil fertilization combination in online Supplementary Table S5.

\section{Relationships among traits}

In the combined analysis, high grain yield was significantly associated with high seedling vigour, large plant height, high stover yield, long panicles, high panicle yield and high average panicle weight, strong panicle compactness, a high number of grains per panicle, and low downy mildew infestation (Table 3). The correlation was nonsignificant for flowering time, panicle circumference and thousand grain weight. The significance of correlation coefficients differed greatly across single environments. For example, seedling vigour and grain yield were not correlated at both Cinzana environments, but highly significantly associated at Maiduguri and Sadoré. High downy mildew infestation, on the other hand, was significantly associated with low grain yield at Cinzana, but the two traits were unrelated at Maiduguri and Sadoré. Flowering time was significantly and positively associated with grain yield only at the high-input environment in Cinzana. Panicle length was significantly associated with grain yield in the combined analysis, at all low-input environments and at the fertilized site at Cinzana. High tillering was associated with higher grain yield at Cinzana and Maiduguri, while there was no significant correlation between these traits in Sadoré.

\section{Patterns of genotype $\times$ environment interaction}

In the AMMI analysis, principal component (PC) 1 explained $56.9 \%$ and PC2 $20.2 \%$ of the total G $\times \mathrm{E}$ interaction (Fig. 1). The three locations (Cinzana, Sadoré and Maiduguri) were clearly separated from each other. The high- and low-input sites exhibited similar influence on the genotypes at Cinzana and Maiduguri, with the highinput site showing stronger interaction especially at Maiduguri. However, at Sadoré, high- and low-input environments were clearly separated from each other. The lowinput environment was showing little interaction and the high-input environment exerted the strongest interaction of all six environments. Genotypes closer to the centre were more stable over all environments.

The estimated AMMI stability values (ASV) for grain yield data revealed a wide range of the tested entries (0.2-10.4). Accessions with higher grain yield stability (lower ASV value) compared with the tested checks were identified; however, none of the accessions out-yielded the on average highest-yielding local checks (online Supplementary Table S6).

\section{Diversity of the tested accessions}

PC 1 and 2 explained 52.4 and $14.4 \%$ of the total variation, respectively (Fig. 2). Accessions could generally not be grouped distinctively by origin. Accessions from Ghana (orange) were negatively associated with all included traits and accessions from Cameroon were among the tallest. However, the observed admixture hinders further association of groups and traits, e.g. accessions from Niger (lightgreen) were found to be both among the tallest and the shortest (Fig. 2).

\section{Evaluation of Striga resistance in Niger}

The evaluation of 81 accessions from the GCP pearl millet reference collection for Striga resistance yielded high repeatabilities among the entries for various Striga resistance measures (Table 4). High repeatabilities were also obtained for flowering time (92\%) and panicle yield (87\%). Certain 


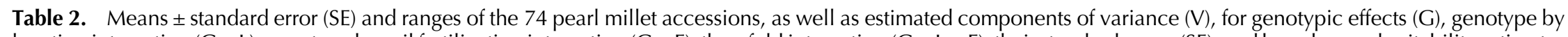

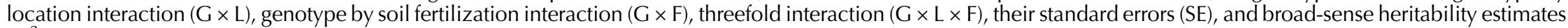
$\left(H^{2}\right)$ for various traits, from the combined analysis across three sites and two soil fertilization treatments

\begin{tabular}{|c|c|c|c|c|c|c|c|c|c|c|c|}
\hline Trait & Mean \pm SE & Range & V $(\mathrm{G})$ & SE & $\mathrm{V}(\mathrm{G} \times \mathrm{L})$ & SE & $V(G \times F)$ & SE & $V(G \times L \times F)$ & SE & $H^{2}$ \\
\hline SVIG & $4.0 \pm 0.2$ & $3.4-4.5$ & $0.02 *$ & 0.01 & $0.03^{* *}$ & 0.01 & 0.00 & - & 0.00 & - & 0.39 \\
\hline DM\% & $20.4 \pm 11.5$ & $2.4-52.5$ & $58.26^{*}$ & 23.14 & $133.85^{* *}$ & 25.75 & 0.00 & - & $30.26^{*}$ & 14.99 & 0.46 \\
\hline FLO & $257.8 \pm 9.2$ & $238.1-286.5$ & $77.47^{* *}$ & 14.38 & $18.85^{* *}$ & 2.73 & 0.00 & - & 1.09 & 0.66 & 0.90 \\
\hline PHT & $194.3 \pm 29.5$ & $119.6-242.4$ & $718.31^{* *}$ & 141.03 & $233.82^{* *}$ & 45.44 & 0.00 & - & $52.78^{*}$ & 22.88 & 0.87 \\
\hline STYD & $256.8 \pm 108.0$ & $75.9-574.8$ & $4623.01^{* *}$ & 1091.45 & 886.05 & 562.73 & 243.60 & 554.70 & 0.00 & 0.79 & 0.70 \\
\hline PLE & $31.9 \pm 11.1$ & $14.3-61.5$ & $100.78^{* *}$ & 17.34 & 2.50 & 1.64 & 0.00 & - & 2.49 & 1.85 & 0.96 \\
\hline CIR & $7.8 \pm 1.0$ & 5.7-10.8 & $0.86^{* *}$ & 0.17 & $0.18^{*}$ & 0.08 & 0.00 & - & $0.19 * *$ & 0.07 & 0.82 \\
\hline TILL & $3.7 \pm 0.6$ & $2.1-6.0$ & $0.22^{* *}$ & 0.06 & $0.09 * *$ & 0.03 & 0.03 & 0.02 & 0.00 & - & 0.52 \\
\hline PYD & $118.7 \pm 51.7$ & $38.6-229.3$ & $1606.96^{* *}$ & 350.05 & $623.73 * *$ & 138.35 & $180.56^{*}$ & 77.40 & 0.00 & - & 0.75 \\
\hline APW & $28.3 \pm 10.2$ & $12.9-54.9$ & $79.44^{* *}$ & 16.43 & $24.1^{* *}$ & 6.04 & 5.21 & 3.62 & 8.98 & 5.10 & 0.82 \\
\hline CMP & $1.8 \pm 0.4$ & $1.1-2.8$ & $0.14^{* *}$ & 0.03 & $0.04^{*}$ & 0.01 & 0.00 & 0.01 & 0.02 & 0.02 & 0.81 \\
\hline GYD & $65.6 \pm 30.3$ & $21.2-137.1$ & $513.82^{* *}$ & 112.50 & $181.77^{* *}$ & 46.30 & 45.97 & 31.74 & 0.00 & - & 0.74 \\
\hline TGW & $7.9 \pm 1.5$ & $4.5-13.5$ & $1.51^{* *}$ & 0.37 & - & - & 0.04 & 0.20 & - & - & 0.75 \\
\hline NGP & $3738.9 \pm 1490.5$ & $1374.3-6556.4$ & $1,785,736.49^{* *}$ & $365,612.39$ & - & - & 0.64 & $108,547.57$ & - & - & 0.86 \\
\hline
\end{tabular}

*, ** Significant at $P=0.05$ and $P=0.01$, respectively.

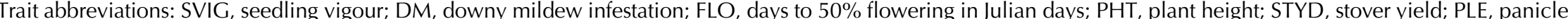

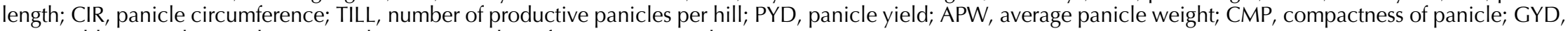
grain yield; TGW, thousand grain weight; NGP, number of grains per panicle. 
Table 3. Pearson coefficients of correlation between grain yield and other traits observed for 74 pearl millet accessions at three sites with two soil fertilization levels (high and low), and combined across all environments

\begin{tabular}{|c|c|c|c|c|c|c|c|}
\hline \multirow[b]{2}{*}{ Trait } & \multicolumn{2}{|l|}{ Cinzana } & \multicolumn{2}{|l|}{ Maiduguri } & \multicolumn{2}{|l|}{ Sadoré } & \multirow[b]{2}{*}{ Combined } \\
\hline & High & Low & High & Low & High & Low & \\
\hline SVIG & 0.05 & 0.21 & $0.48^{* * *}$ & $0.66^{* * *}$ & $0.62^{* * *}$ & $0.64 * * *$ & $0.71 * * *$ \\
\hline $\mathrm{DM}$ & $-0.50^{* * *}$ & $-0.38^{*}$ & -0.33 & -0.30 & -0.10 & -0.07 & $-0.39^{*}$ \\
\hline FLO & $0.43^{* *}$ & 0.32 & -0.05 & 0.04 & -0.06 & -0.01 & 0.18 \\
\hline PHT & $0.57^{* * *}$ & $0.48^{* * *}$ & $0.40^{* *}$ & $0.53^{* * *}$ & 0.30 & $0.67^{* * *}$ & $0.61^{* * *}$ \\
\hline STYD & $0.36^{*}$ & - & $0.97^{* * *}$ & $0.95^{* * *}$ & $0.63^{* * *}$ & $0.83^{* * *}$ & $0.70^{* * *}$ \\
\hline PLE & $0.35^{*}$ & $0.47^{* * *}$ & 0.24 & $0.42^{* *}$ & 0.32 & $0.54^{* * *}$ & $0.50^{* * *}$ \\
\hline $\mathrm{CIR}$ & 0.02 & 0.23 & 0.14 & 0.02 & 0.11 & 0.34 & 0.12 \\
\hline TILL & $0.44^{* *}$ & $0.49^{* * *}$ & $0.37^{*}$ & $0.36^{*}$ & 0.25 & 0.35 & 0.23 \\
\hline PYD & $0.91^{* * *}$ & $0.95^{* * *}$ & $0.99^{* * *}$ & $0.99^{* * *}$ & $0.97^{* * *}$ & $0.98^{* * *}$ & $0.98^{* * *}$ \\
\hline APW & $0.60^{* * *}$ & 0.29 & $0.39 *$ & $0.60^{* * *}$ & $0.52^{* * *}$ & $0.79 * * *$ & $0.66^{* * *}$ \\
\hline CMP & 0.27 & $0.47^{* * *}$ & 0.11 & 0.34 & $0.41^{* *}$ & $0.59^{* * *}$ & $0.50^{* * *}$ \\
\hline TGW & - & - & - & - & 0.24 & 0.24 & -0.08 \\
\hline NGP & - & - & - & - & $0.56^{* * *}$ & $0.75^{* * *}$ & $0.70^{* * *}$ \\
\hline
\end{tabular}

*,**,*** Significant at $P<0.05, P<0.01$ and $P<0.001$, respectively.

Trait abbreviations: see Table 2 .

accessions were found highly resistant to Striga, but none of the accessions out-yielded the check or showed a higher Striga resistance (Table 4). The highest yielding accession was G10 from Mali with $111.2 \mathrm{~g} / \mathrm{m}^{2}$ (panicle yield). The accessions G33 from Benin and G64 from Togo were the best accessions regarding Striga resistance (ASVPC). The complete results are shown in online Supplementary Table S7.

\section{Discussion}

\section{General comments on the characterization trials}

The three test sites differed largely for planting date, the total amount of rainfall and rainfall distribution. The outstandingly high rainfall amount during September at Cinzana led to the positive association between grain yield and flowering time at this location, and was disfavouring early-flowering accessions whose pollen was thereby washed away. This could be the reason for the moderate yield level at Cinzana despite the high precipitation. The high amount of rain at Cinzana promoted downy mildew development and led to the significant negative correlation between grain yield and downy mildew susceptibility.

The Maiduguri site was characterized by late planting, but the late rains in October, after flowering, helped the plants to produce grains. The differences between the lowinput and the fertilized trial at Maiduguri were small for most traits, including grain yield. The high rainfall in the month of sowing $(266 \mathrm{~mm})$ caused leaching of the applied fertilizer at Maiduguri. This might have converged the two different fertilization treatments at Maiduguri and led to these similar yield levels.

The Sadoré site received lowest rainfall amounts in September and October, and especially its low-input trial suffered from the combination of low soil fertility and terminal drought stress. As described by Valluru et al. (2010) and Beggi et al. (2014), phosphorus is essential for plant development. Drought stress can reduce phosphorus uptake (Hash et al., 2002; Sinclair and Vadez, 2002). Pearl millet can cope with early drought stress, but is relatively susceptible to terminal drought stress (Mahalakshmi et al., 1987). Thus, it can be assumed that in the low-input trial at Sadoré, the plants were not able to compensate the lack of fertilizer and performed much worse than in the high-input trial.

\section{Agro-morphological differentiation among the WCA accessions of the GCP pearl millet reference collection}

The present study revealed significant genetic variation among the WCA accessions of the GCP pearl millet reference collection for all agro-morphological traits assessed. The characterization data, made available in online Supplementary Tables S4-S11, can enable breeders all over the world to select trait-specific germplasm for further use in their breeding programmes. The estimated repeatabilities in our study were in general reasonably high for 


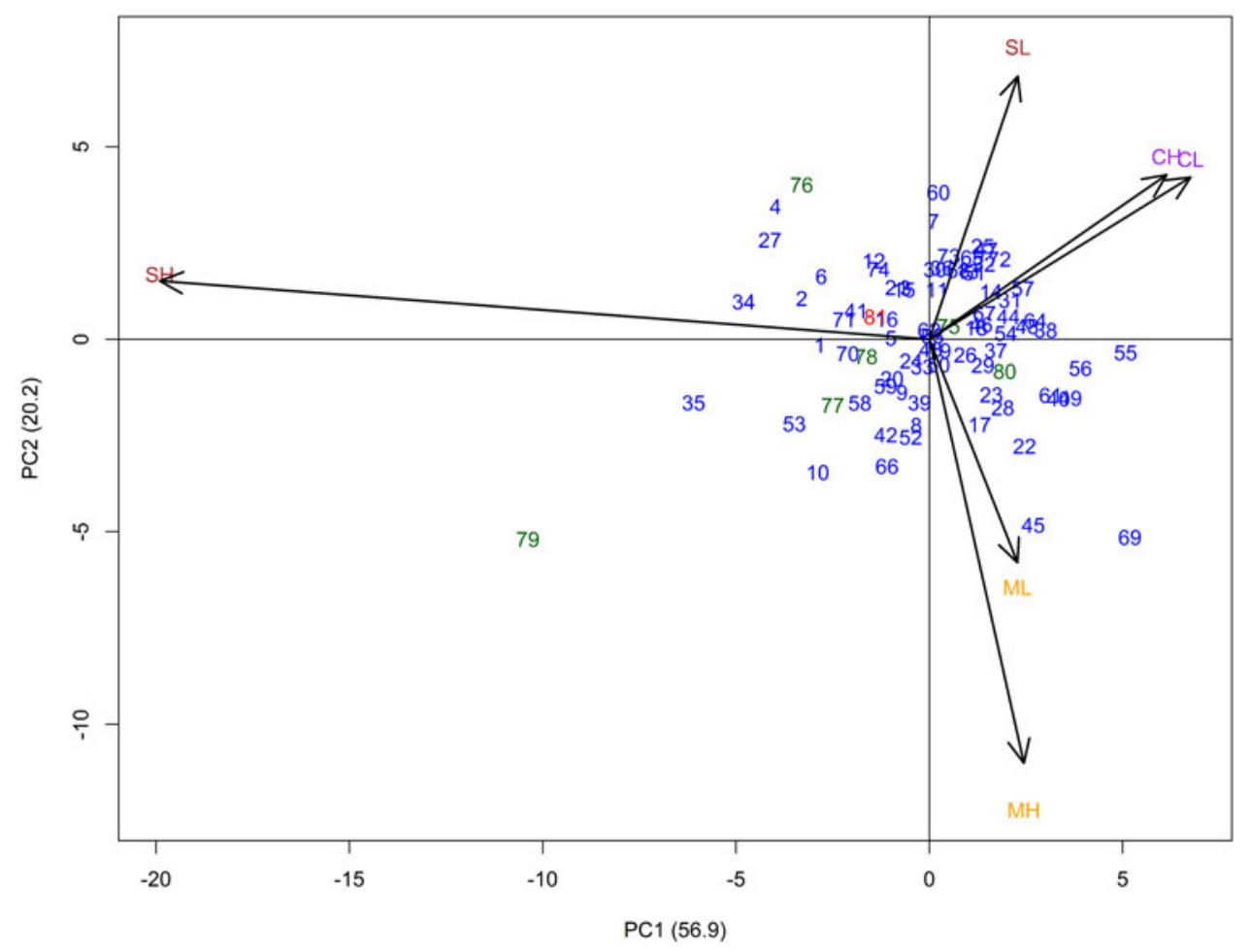

Fig. 1. AMMI biplot illustrating relationships among test sites and entries for 74 GCP pearl millet accessions (blue), six improved checks (green) and the average of the local checks (red) evaluated at three sites (Cinzana (C) in Mali, Maiduguri (M) in Nigeria, and Sadoré (S) in Niger) with two soil fertilization levels per site (low (L) and high (H)-input) using single environment adjusted means (for assignment of entry numbers, see online Supplementary Table S1).

targeting desirable traits in future breeding programs. Also, the estimated repeatabilities per trait were within the same range for both, low-input and fertilized conditions, apart from single exceptions. This indicates that the collection can be useful in breeding programmes targeting intensified conditions as well as breeding programmes targeting lowinput conditions. The observed ranges of most agromorphological traits were of the same magnitude as those reported in similar studies (Bhattacharjee et al., 2007; Padilla, 2007; Upadhyaya et al., 2007, 2011; Bashir et al., 2013; Pucher et al., 2015). The ranges observed in this subset of accessions were, however, smaller than those observed in the complete core and complete mini core collections (Bhattacharjee et al., 2007; Upadhyaya et al., 2011). Two possible explanations are most likely responsible for this deviation. First, the number of evaluated accessions was much smaller in this study than in those mentioned before. Second, the accessions described in those studies were tested in a single environment, while in this study genotypes were tested in six environments, which likewise causes shrinkage of the range towards the mean.

The Striga resistance trial conducted at Sadoré in Niger also revealed highly significant differences among the accessions, and allowed identification of potential new resistance sources. However, these results need further validation, since Striga resistance is usually strongly influenced by genotype by environment interactions (Haussmann et al., 2001; Badu-Apraku, 2010; Kountche et al., 2013). Kountche et al. (2013) tested progenies from the Striga-resistant pearl millet genepool in Mali and Niger and found the $\mathrm{G} \times \mathrm{E}$ variance being higher than the genetic variance for Striga resistance, indicating that different varieties ranked best for Striga resistance in Niger versus Mali. Haussmann et al. (2001) tested 50 sorghum varieties at two locations in both Mali and Kenya and showed that varieties having high resistance to Striga at one test location were possibly susceptible at another test location. Furthermore, Yoshida et al. (2010) used SSR markers to reveal a wide genetic diversity in Striga itself. Therefore, resistant accessions identified in the present Striga resistance trial in Niger should be re-evaluated before being used as resistance source, especially in other countries than our test country Niger.

\section{Trait-specific germplasm identification}

The positive correlation between seedling vigour and grain yield in Maiduguri, Sadore and the combined analysis underlined the importance of quick seedling development 


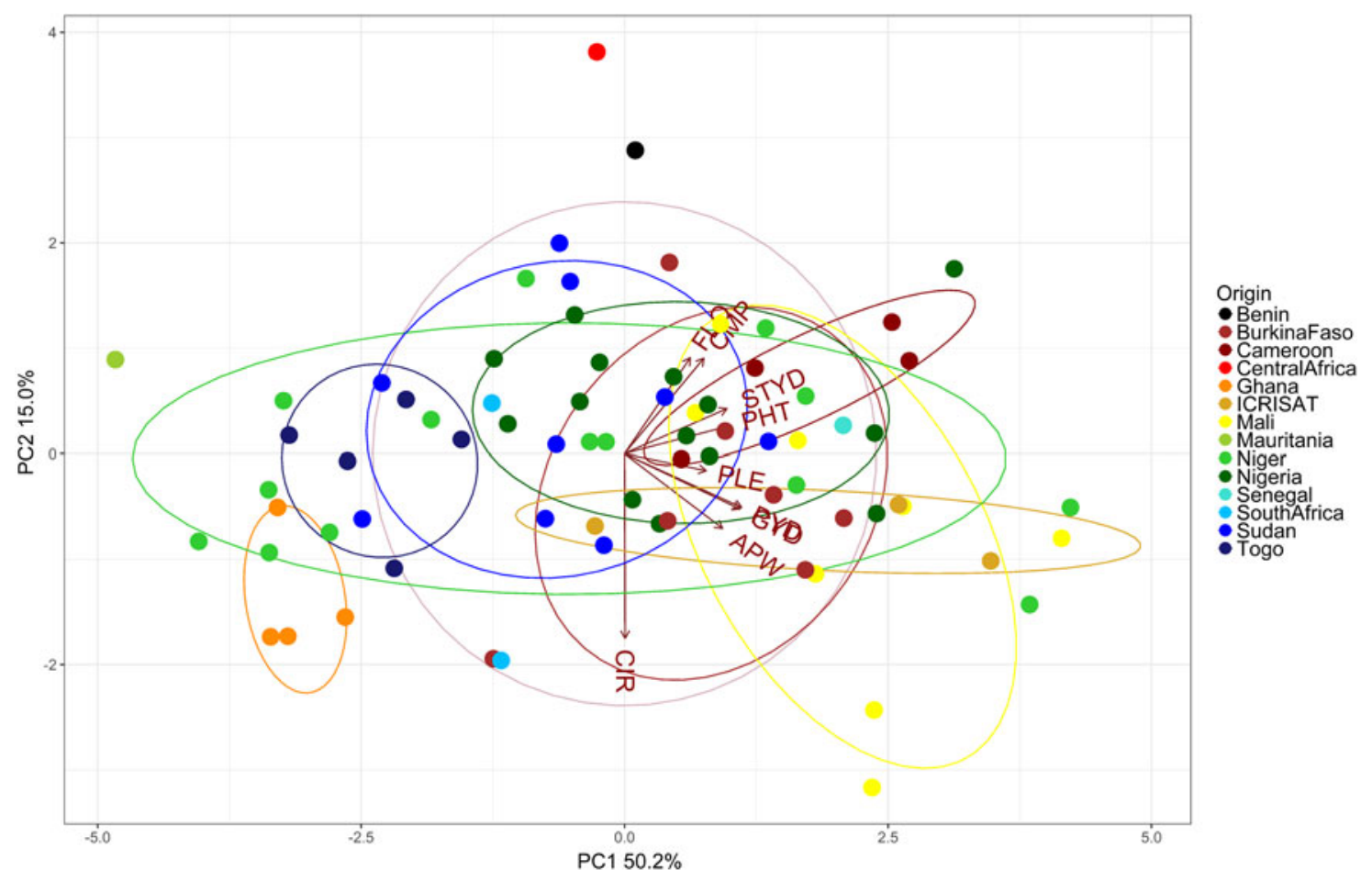

Fig. 2. Principal component analysis (PCA) illustrating relationships between 74 pearl millet accessions (dots) evaluated at three sites (Cinzana in Mali, Maiduguri in Nigeria, Sadoré in Niger) with two soil fertilization levels per site (low- and high-input). Vectors indicate traits (Trait abbreviations, see Table 2).

for high yields, especially under dryland conditions, which is in accordance to the work of Manga and Yadav (1995).

Data from Maiduguri and Sadoré can be used to identify entries with good seedling vigour. Cinzana on the other hand, due to the higher precipitation, was the best site for identification of downy mildew-resistant accessions, and accessions with productive tillering capacity. However, due to usually high genotype by environment interaction for downy mildew resistance (Kountche et al., 2013), it needs to be validated whether the resistant sources identified at Cinzana in Mali remain resistant and could be used as resistance source also in other sites. The high heritability estimates derived from the combined analysis across locations for flowering time, plant height, panicle length, circumference, compactness and for number of grains per panicle indicated good scope for selection of entries with a specific expression of these traits using means across the three test sites. A precise, trait-specific selection of genotypes is crucial for distinct environmental conditions. Certain traits like downy mildew resistance are essential in more humid regions such as the Sudanean zone of WCA, while early flowering is important to avoid terminal drought stress in the Sahelian zone of WCA (Bidinger et al., 1987; Pucher et al., 2015).

\section{Observed patterns of $G \times E$ interaction}

Separation of the total $G \times E$ variance into interaction variance components with locations $(G \times L)$, soil fertilization levels $(G \times F)$ and the threefold interaction variance $(\mathrm{G} \times \mathrm{L} \times \mathrm{F})$ is recommended to determine the appropriate selection strategy (Annicchiarico, 2002). In addition, the size of the genotype by year $(G \times Y)$ interaction determines how much priority needs to be given to yield stability over years. In the framework of this study, it was not possible to estimate $G \times Y$ interaction. Nevertheless, the genetic variance explained the largest part of the total variance for all traits except seedling vigour and downy mildew susceptibility. By separating the interaction variance for all traits, it could be shown that its largest part was explained by interactions with the location effect. The $G \times F$ variance was neglectable and the threefold interaction played only a minor role in this characterization study. In the case of seedling vigour, the large $\mathrm{G} \times \mathrm{L}$ interaction can be explained by the differences in precipitation among the three locations. Kountche et al. (2013) and Pucher et al. (2015) also found high $\mathrm{G} \times \mathrm{E}$ interactions for reaction to downy mildew. The downy mildew pathogen is, like pearl millet, highly allogamous. The pathogen's virulence can match the resistance of the millet population in regions 
Table 4. Repeatabilities (Rep \%), accession means \pm standard error (SE), ranges, and performance of the best check for various traits estimated in the pearl millet Striga resistance trial conducted at Sadoré in 2009

\begin{tabular}{llccc}
\hline Trait & Rep $\%$ & Accession mean \pm SE & Range among accessions & Best improved or local check \\
\hline DM\% & 92 & $11.4 \pm 17.3$ & $0.0-100.0$ & 39.3 \\
FLO & 92 & $247.5 \pm 9.0$ & $220.6-269.2$ & - \\
PHT & 92 & $155.0 \pm 36.5$ & $61.7-244.4$ & 255 \\
PLE & 97 & $30.7 \pm 11.1$ & $7.9-63.0$ & 75.2 \\
PYD & 87 & $26.9 \pm 21.8$ & $0.0-111.2$ & 132.2 \\
DES & 72 & $230.3 \pm 4.2$ & $221.9-242.4$ & - \\
NS66 & 64 & $22.4 \pm 20.2$ & $0.0-112.4$ & 2.9 \\
SEV66 & 66 & $45.2 \pm 43.0$ & $0.0-258.8$ & 17.7 \\
NS86 & 65 & $184.0 \pm 129.6$ & $0.0-730.9$ & 29.9 \\
NS105 & 65 & $165.0 \pm 120.6$ & $0.0-710.6$ & 16.3 \\
MSTR & 67 & $128.0 \pm 88.4$ & $0.0-507.0$ & 0.0 \\
ASVPC & 91 & $650.4 \pm 1484.4$ & $0.0-11,140.2$ & \\
\hline
\end{tabular}

Trait abbreviations: see Table 2; DES, days to first Striga emerging in the plot in Julian days; NSx, number of emerged Striga plants at $x$ days after planting (dap). SEVx, Striga severity at x dap; MSTR, mean number of emerged Striga across three counts; ASVPC, area under Striga severity progress curve.

Values smaller than zero (due to statistical adjustment) were corrected to zero.

they occur together (depending on the history of the field), causing the high interaction variance (Pucher et al., 2015).

In our study, the $\mathrm{G} \times \mathrm{E}$ interaction for grain yield was relatively small compared with results from Bashir et al. (2013) and Pucher et al. (2015, 2016). Nevertheless, G × L interaction was still explaining a significant part of the total variation. The AMMI biplot clearly separated the three locations, thereby emphasizing the importance of local adaption. The positive correlation between grain yield and flowering time at Cinzana underlined the specific adaptation of later flowering genotypes to this location, while grain yield was not correlated with flowering time at Maiduguri and Sadoré.

Low- and high-input fields at Cinzana and Maiduguri were grouped closely together, but Sadoré was depicted differently. The average grain yield performance at Sadore under high-input conditions was outstanding (online Supplementary Table S2). The weather conditions at Sadoré, as described before, did not mask the fertilizer effect (as was the case at the other two locations). This explains the clear separation of the high-input environment from all other trials, actually pointing to the existence of $\mathrm{G} \times \mathrm{F}$ interaction at this location. Gemenet et al. (2014, 2016) also observed specific adaptation to either low soil fertility or intensified conditions among West African pearl millet accessions. These authors also encountered masked fertilizer effects at some locations. Precipitation seemed to determine the location effect and had a high influence on the yield level. While the AMMI analysis identified entries with relatively stable yields across the six test sites, these results need to be treated with caution. Bashir et al. (2014a) and Gemenet et al. (2014) tested their pearl millet varieties across several years and observed large $\mathrm{G} \times \mathrm{Y}$ interaction effects. High inter-annual rainfall variability is common in WCA (Haussmann et al., 2012) and contributes largely to these year effects and the $G \times Y$ interactions. Multi-year trials are therefore necessary to validate the repeatability of observed $\mathrm{G} \times \mathrm{L}$ and $\mathrm{G} \times \mathrm{F}$ patterns and to identify specific genotypes that suit distinct regions reliably.

\section{Diversity analysis and implications for heterotic grouping}

The PCA indicated strong genetic admixture of genotypes, independent of the country of origin, and it was hardly possible to identify distinct clusters. WCA is most likely the centre of origin of pearl millet (Brunken et al., 1977; Oumar et al., 2008; Tostain and Marchais, 1993) and a vast gene flow caused by high outcrossing rates of $\sim 85 \%$ (Sandmeier, 1993; vom Brocke et al., 2003) is characteristic for this crop. Drought-tolerant, wind-borne pollen (Hoekstra et al., 2006) might contribute to these high outcrossing rates.

Genetic diversity studies using different molecular markers are likewise concluding that strong admixture among pearl millet varieties is predominant and definition of distinct groups is not evident (Lewis, 2010; Stich et al., 2010; Bashir et al., 2014b; Pucher et al., 2015).

Therefore, genetic diversity studies should be combined with combining ability studies to define initial heterotic 
groups, which are the foundation for maximum exploitation of heterosis in general and for successful and sustainable hybrid breeding in particular (Melchinger and Gumber, 1998). The great potential of pearl millet hybrids has already been confirmed (Ouendeba et al., 1993; Bidinger et al., 1994, 2005; Yadav et al., 2000) and the initial release of hybrids in India in the mid-1960s sixties contributed largely to the overall productivity. It increased from $5.2 \mathrm{~kg} / \mathrm{ha} / \mathrm{yr}$ (1950-1965) to $24.0 \mathrm{~kg} / \mathrm{ha} / \mathrm{yr}(1996-2012)$ (Yadav and Rai, 2013). Genetic initial combining ability studies among WCA pearl millets were conducted in pearl millet, but without finding clear patterns (Pucher et al., 2016). However, promising hybrids developed from Nigerien and Senegalese varieties were found. More extensive combining ability studies with larger sets of genotypes could help to define heterotic groups.

\section{Implications for conserving pearl millet genetic resources}

The local checks (which differed among locations) were among the best entries in terms of mean grain yield at all locations. None of the tested accessions out-yielded the local checks. The generally inferior performance of the gene bank accessions observed in this study and similar results of Padilla (2007), who found only two accessions out of 504 from a global pearl millet core collection with a superior performance in comparison with local checks, lead to the following hypotheses:

- The accessions conserved in the gene bank outside their country of origin may partially lose their local adaptation over time. This will possibly lead to a lower performance in their original environment. Probable causes are inbreeding depression due to low population size (genetic bottlenecks, for example during cluster bagging) and sampling effects, and natural selection happening in a different regeneration environment.

- Farmer's varieties and improved varieties maintained in a region may change towards better adaptation over time, leading to better performance at the test sites, compared with original seed samples collected a long time ago and stored in a gene bank.

The Food and Agriculture Organization of the United Nations (FAO) commonly recommend conserving seeds ex-situ in gene banks. Nevertheless, the risk of collecting and preserving an undersized number of effective alleles or missing prospective alleles in core collections as well as not having the possibility to adapt the accessions to modern demands or to their changing native environment must not be underestimated (Pistorius, 1997).
The second hypothesis is supported by the work of Bezançon et al. (2009), who studied changes in the diversity of pearl millet and sorghum in Niger populations between 1976 and 2003. Concerns that these crops suffer from genetic erosion were not confirmed. However, there was a shift towards earlier flowering at the end of the examined period of 27 years. Brown (1989) suggested core collections of $10 \%$ of the complete collection, without exceeding the size of 3000 accessions, to capture $\sim 70 \%$ of the total variation. The ICRISAT pearl millet core collection might be too small with 504 out of 21,456 entries ( 2.3\%) (Upadhyaya et al., 2007) to cover the large diversity of pearl millet. Especially under the assumption that $5-10 \%$ of alleles are lost in every generation, while being maintained and regrown in core collections (Burton, 1976). The risk of creating or already having created a 'bottle neck' by sampling too little or closely related individual plants should also be taken into consideration.

\section{Conclusions}

The evaluation of the WCA pearl millet accessions of the GCP reference collection displayed once more the impressive diversity present in WCA pearl millet. Large significant genetic variation for a multitude of agro-morphological traits was observed. The provided list of adjusted means for numerous traits of all tested genotypes at each site and combined across all sites (online Supplementary Tables S4, S5 and S7) is meant to support NARS (National Agricultural Research Systems) breeders and will facilitate the decision on selecting adequate parents, bearing superior traits, for future breeding programmes.

Within the evaluated subsample, several accessions being well adapted to one of the test environments and/ or possessing useful traits were identified. In addition, few accessions with high yield and stability for developing high yielding varieties with a smaller $\mathrm{G} \times \mathrm{E}$ interaction than the local checks were found (online Supplementary Tables S6). These accessions need to be further validated across multiple years. However, none of the accessions was superior to local checks in their respective environment.

The experiences from this project and the mentioned studies underline the importance to develop and test appropriate in situ conservation strategies for plant genetic resources to maintain or enhance their adaptation to changing environments. Secondly, there may be a need to verify present ex situ conservation methods, especially for outcrossing species such as pearl millet, with the following questions to be investigated: Do we maintain sufficiently large population size during collection and regeneration of accessions that represent very heterogeneous and heterozygous population varieties? Can we avoid natural 
selection effects during regeneration that is performed far away from the geographic origin of the accession? Are there allele frequency changes after a certain number of regeneration events due to sampling effects and (unwanted) selection? If yes, for which traits and at which rate? Nevertheless, the development and preservation of germplasm collections ex situ are important to maintain the rich genetic diversity that exists in pearl millet.

\section{Supplementary material}

The supplementary material for this article can be found at https://doi.org/10.1017/S1479262117000272

\section{Acknowledgements}

The financial support from the Global Crop Diversity Trust, Trust grant no: GS08024, is gratefully acknowledged. HD Upadhyaya (ICRISAT-India) kindly provided the seed from the ICRISAT genebank in Patancheru, India. In addition, the authors would like to thank the following individuals for technical assistance during seed multiplication and accession characterization: A Abarchi, H Adamaou, D Lankoande, $\mathrm{T}$ Boye, A Boubacar (ICRISAT-Niger), S Muhtah (LCRI-Nigeria), M Mariko (IER-Mali). The Ph.D. stipend for FT Sattler was funded by the German Ministry of Economic Cooperation and Development (BMZ, GIZ Project No: 13.1432.7-001.00 and Contract No: 81170266). Finally, we thank the McKnight Foundation Collaborative Crop Research Program for the discretionary research funds provided to BIG Haussmann.

\section{References}

Annicchiarico P (2002) Analysis of variance (ANOVA) and estimation of variance components. In: Annicchiarico P (ed.) Genotype $\times$ Environment Interactions: Challenges and Opportunities for Plant Breeding and Cultivar Recommendations. FAO Plant Production and Protection Paper No. 174. Rome, Italy: Food and Agriculture Organization of the United Nations, pp. 21-29.

Badu-Apraku B (2010) Effects of recurrent selection for grain yield and Striga resistance in an extra-early maize population. Crop Science 50: 1735-1743.

Bashir EMA, Ali AM, Ali AM, Melchinger AE, Parzies HK and Haussmann BIG (2013) Characterization of Sudanese pearl millet germplasm for agro-morphological traits and grain nutritional values. Plant Genetic Resources 12: 1-13.

Bashir EMA, Ali AM, Ali AM, Ismail MI, Parzies HK and Haussmann BIG (2014a) Patterns of pearl millet genotype-by-environment interaction for yield performance and grain iron $(\mathrm{Fe})$ and zinc ( $\mathrm{Zn})$ concentrations in Sudan. Field Crops Research 166: 82-91.

Bashir EMA, Ali AM, Ali AM, Mohamed ETI, Melchinger AE, Parzies HK and Haussmann BIG (2014b) Genetic diversity of Sudanese pearl millet (Pennisetum glaucum (L.) R. Br.) landraces as revealed by SSR markers, and relationship between genetic and agro-morphological diversity. Genetic Resources and Crop Evolution 62: 579-591.

Beggi F, Haussmann BIG, Falalou H, Gemenet DC and Buerkert A (2014) Early phosphorus efficiency of 102 pearl millet varieties from West Africa. In: Beggi $\mathrm{F}$ (ed.) Effects of phosphorus and water stress on shoot and root growth and on mycorrbization of different pearl millet (Pennisetum glaucum (L.) R. Br.) varieties from West Africa. $\mathrm{PhD}$ thesis, University of Kassel, Witzenhaussen, Germany.

Bezançon G, Pham JL, Deu M, Vigouroux Y, Sagnard F, Mariac C, Kapran I, Mamadou A, Gérard B, Ndjeunga J and Chantereau $\mathrm{J}$ (2009) Changes in the diversity and geographic distribution of cultivated millet (Pennisetum glaucum (L.) R. Br.) and sorghum (Sorghum bicolor (L.) Moench) varieties in Niger between 1976 and 2003. Genetic Resources and Crop Evolution 56: 223-236.

Bhattacharjee R, Khairwal IS, Bramel PJ and Reddy KN (2007) Establishment of a pearl millet [Pennisetum glaucum (L.) $\mathrm{R}$. Br.] core collection based on geographical distribution and quantitative traits. Euphytica 155: 35-45.

Bidinger FR, Mahalakshimi V and Rao GDP (1987) Assessment of drought resistance in pearl millet [Pennisetum americanum (L.) Leeke]. II Estimation of genotype response to stress. Australia Journal of Agricultural Research 38: 37-48.

Bidinger FR, Weltzien E, Mahalakshmi RV, Singh SD and Rao KP (1994) Evaluation of landrace topcross hybrids of pearl millet for arid zone environments. Euphytica 76: 215-226.

Bidinger FR, Raj AGB, Abraha N, Ali AM, Obilana AB and Jones RB (2005) Topcross hybrids as an entry into commercial seed production of pearl millet in Eastern Africa. Experimental Agriculture 41: 335-356.

Brown AHD (1989) Core collections: a practical approach to genetic resources management. Genome 31: 818-824.

Brunken J, de Wet JMJ and Harlan JR (1977) The morphology and domestication of pearl millet. Economic Botany 31: 163-174.

Burton GW (1976) Gene loss in pearl millet germplasm pools. Crop Science 16: 251.

Butler DG, Cullis BR, Gilmour AR and Gogel BJ (2009) Analysis of mixed models for $S$ language environments. ASReml-R Reference Manual. Brisbane, Queensland, Australia: The State of Queensland, Dep. of Primary Industries and Fisheries.

de Mendiburu F (2016) Agricolae: Statistical Procedures for Agricultural Research. R package version 1. 2-4. http:// CRAN.R-project.org/package=agricolae

Gemenet DC, Hash CT, Sy O, Zangre RG, Sanogo MD, Leiser WL, Parzies HK and Haussmann BIG (2014) Pearl millet inbred and testcross performance under low phosphorus in West Africa. Crop Science 54: 2574-2585.

Gemenet DC, Beggi F, Hash CT, Sy O, Sanogo MD, Zangre RG, Falalou H, Buerkert A and Haussmann BIG (2015a) Towards understanding the traits contributing to performance of pearl millet open-pollinated varieties in phosphorus-limited environments of West Africa. Plant and Soil 407: 243-259.

Gemenet DC, Hash CT, Sanogo MD, Sy O, Zangre RG, Leiser WL and Haussmann BIG (2015b) Phosphorus uptake and utilization efficiency in West African pearl millet inbred lines. Field Crops Research 171: 54-66.

Gemenet DC, Leiser WL, Beggi F, Herrmann LH, Vadez V, Rattunde HFW, Weltzien E, Hash CT, Buerkert A and Haussmann BIG (2016) Overcoming phosphorus deficiency in West African pearl millet and sorghum production systems: promising options for crop improvement. Frontiers in Plant Science 7, 1389. 
Genesys (2016). https://www.genesys-pgr.org/de/wiews/IND002 viewed 3 February 2017.

Hash CT, Schaffert RE and Peacock JM (2002) Prospects for using conventional techniques and molecular biological tools to enhance performance of 'orphan' crop plants on soils low in available phosphorus. Plant Soil 245: 135-146.

Haussmann BIG, Boureima SS, Kassari IA, Moumouni KH and Boubacar A (2007) Mechanisms of adaptation to climate variability in West African pearl millet landraces - a preliminary assessment. SAT eJournal 3: 2-4.

Haussmann BIG, Hess DE, Welz HG and Geiger HH (2000) Improved methodologies for breeding striga-resistant sorghums. Field Crops Research 66: 195-211.

Haussmann BIG, Hess DE, Reddy BVS, Mukuru SZ, Kayentao M, Welz HG and Geiger GG (2001) Pattern analysis of genotype $\times$ environment interaction for striga resistance and grain yield in African sorghum trials. Euphytica 122: 297-308.

Haussmann BIG, Rattunde HF, Weltzien-Rattunde E, Traoré PSC, vom Brocke K and Parzies HK (2012) Breeding strategies for adaptation of pearl millet and sorghum to climate variability and change in West Africa. Journal of Agronomy and Crop Science 198: 327-339.

Hoekstra FA, Crowe LM and Crowe JH (2006) Differential desiccation sensitivity of corn and Pennisetum pollen linked with their sucrose contents. Plant, Cell E Environment 12: 83091.

Kountche BA, Hash CT, Dodo H, Laoualy O, Sanogo MD, Timbeli A, Vigouroux Y, This D, Nijkamp R and Haussmann BIG (2013) Development of a pearl millet striga-resistant genepool: response to five cycles of recurrent selection under striga-infested field conditions in West Africa. Field Crops Research 154: 82-90.

Lewis LR (2010) Biogeography and genetic diversity of pearl millet (Pennisetum glaucum) from Sahelian Africa. The Professional Geographer 62: 377-394.

Mahalakshmi V, Bidinger FR and Raju DS (1987) Effect of timing of water deficit on pearl millet (Pennisetum americanum). Field Crops Research 15: 327-339.

Manga VK and Yadav OP (1995) Effect of seed size on developmental traits and ability to tolerate drought in pearl millet. Journal of Arid Environments 29: 169-172.

Melchinger AE and Gumber RK (1998) Overview of heterosis and heterotic groups in agronomic groups. In: Larnkey KR and Staub JE (eds) Concepts and Breeding Of Heterosis in Crop Plants. CSSA Spec. Publ. 25. Madison, WI: CSSA, pp. 29-44.

Ouendeba B, Ejeta G, Nyquist WE, Hanna W and Kumar A (1993) Heterosis and combining ability among African landraces. Crop Science 33: 735-739.

Oumar I, Mariac C, Pham JL and Vigouroux Y (2008) Phylogeny and origin of pearl millet (Pennisetum glaucum [L.] R. Br) as revealed by microsatellite loci. Theoretical and Applied Genetics 117: 489-497.

Padilla JC (2007) Phenotypic characterization of a pearl millet [Pennisetum glaucum (L.) R. Br.] core collection under field conditions in Niger. MSc thesis, University of Hohenheim, Stuttgart, Germany.

Pattanashetti SK, Dwivedi SL, Vetriventhan M and Reddy KN (2016) Pearl millet. In: Singh M and Upadhyaya HD (eds) Genetic and Genomic Resources for Grain Cereals Improvement. San Diego, USA: Academic Press, pp. 253-289.
Pistorius R (1997) Scientists, Plants, and Politics: A History of the Plant Genetic Resources Movement. Rome, Italy: Bioversity International.

Pucher A, Høgh-Jensen H, Gondah J, Hash CT and Haussmann BIG (2014) Micronutrient density and stability in West African pearl millet - potential for biofortification. Crop Science 54: 1709-1720.

Pucher A, Sy O, Angarawai II, Gondah J, Zangre R, Ouedraogo M, Sanogo MD, Boureima S, Hash CT and Haussmann BIG (2015) Agro-morphological characterization of West and Central African pearl millet accessions. Crop Science 55: 737.

Pucher A, Sy O, Sanogo MD, Angarawai II, Zangre R, Ouedraogo M, Boureima S, Hash CT and Haussmann BIG (2016) Combining ability patterns among West African pearl millet landraces. Field Crops Research 195: 9-20.

R Development Core Team (2012) $R$ : A Language and Environment for Statistical Computing. 2.14.2. Vienna, Austria: R Foundation for Statistical Computing. http://www. R-project.org/, ISBN 3-900051-07-0.

Sandmeier M (1993) Selfing rates of pearl millet (Pennisetum typhoides Stapf and Hubb.) under natural conditions. Theoretical and Applied Genetics 86: 513-517.

Sinclair TR and Vadez V (2002) Physiological traits for crop yield improvement in low N and P environment. Plant Soil 245: 1-15.

Stich B, Haussmann BIG, Pasam R, Bhosale S, Hash CT, Melchinger AE and Parzies HK (2010) Patterns of molecular and phenotypic diversity in pearl millet [Pennisetum glaucum (L.) R. Br.] from West and Central Africa and their relation to geographical and environmental parameters. $B M C$ Plant Biology 10: 216.

Stram DO and Lee JW (1994) Variance components testing in the longitudinal mixed effects model. Biometrics 50: 1171-1177.

Tostain S and Marchais L (1993) Evaluation de la diversité génétique des mils (Pennisetum glaucum (L.) R. Br.) au moyen de marqueurs enzymatiques et relations entre formes sauvages et cultivées. In: Serge H (ed.) Le mil en Afrique: diversité génétique et agro-physiologique: potentialités et contraintes pour l'amélioration et la culture. Paris, France: Orstrom, pp. 33-56.

Upadhyaya HD, Reddy KN and Gowda CLL (2007) Pearl millet germplasm at ICRISAT genebank - status and impact. SAT eJournal 3: 1-5.

Upadhyaya HD, Yadav D, Reddy KN, and Gowda CLL and Singh S (2011) Development of pearl millet minicore collection for enhanced utilization of germplasm. Crop Science 51: 217-223.

Valluru R, Vadez V, Hash CT and Karanam PA (2010) Minute P application contributes to a better establishment of pearl millet (Pennisetum glaucum (L.) R. Br.) seedling in P deficient soils. Soil Use and Management 26: 36-43.

Vom Brocke K, Christinck A, Weltzien-R E, Presterl T and Geiger HH (2003) Farmers' seed systems and management practices determine pearl millet genetic diversity patterns in semiarid regions of India. Crop Science 43: 1680-1689.

Yadav OP and Rai KN (2013) Genetic improvement of pearl millet in India. Agricultural Research 2: 275-292.

Yadav OP, Weltzien-Rattunde E, Bidinger FR and Mahalakshmi V (2000) Heterosis in landrace-based topcross hybrids of pearl millet across arid environments. Euphytica 112: 285-295.

Yoshida S, Ishida JK, Kamal NM, Ali AM, Namba S and Shirasu K (2010) A full-length enriched cDNA library and expressed sequence tag analysis of the parasitic weed, Striga Hermonthica. BMC Plant Biology 10: 55. 